\title{
Synergistic antibacterial effects of carvacrol and $\varepsilon$-polylysine
}

\author{
Lu Gao ${ }^{1,2}$, Yuan Hu${ }^{1}$, Mei-ling Sun ${ }^{1}$, Xiang-feng Zheng', Ming Yang', Sheng-qi Rao ${ }^{1,3,4, *}$ \\ ${ }^{1}$ College of Food Science and Engineering, Yangzhou University, Yangzhou, Jiangsu, China; ${ }^{2}$ Jiangsu Key Laboratory of \\ Dairy Biotechnology and Safety Control, Yangzhou University, Yangzhou, Jiangsu, China; ${ }^{3}$ Postdoctoral Mobile Station \\ of Biology, College of Bioscience and Biotechnology, Yangzhou University, Yangzhou, Jiangsu, China; ${ }^{4}$ Key Laboratory \\ of Prevention and Control of Biological Hazard Factors (Animal Origin) for Agri-food Safety and Quality, Ministry of \\ Agriculture of China, Yangzhou, Jiangsu, China
}

"Corresponding author: Sheng-qi Rao, College of Food Science and Engineering, Yangzhou University, Yangzhou 225127, Jiangsu, China. Email: sqrao@yzu.edu.cn

Received: 14 June 2021; Accepted: 29 July 2021; Published: 22 November 2021

(c) 2021 Codon Publications

OPEN ACCESS (C) (1) (2)(2)

ORIGINAL RESEARCH

\begin{abstract}
This study aimed to evaluate the antimicrobial efficacy of the combination of $\varepsilon$-polylysine ( $\varepsilon$-PL) and carvacrol (Car) against foodborne pathogens, Escherichia coli and Staphylococcus aureus. The minimum inhibitory concentrations (MICs) of $\varepsilon$-PL (Car) against E. coli and S. aureus were $25 \mu \mathrm{g} / \mathrm{mL}(320 \mu \mathrm{g} / \mathrm{mL})$ and $12.5 \mu \mathrm{g} / \mathrm{mL}(320 \mu \mathrm{g} /$ $\mathrm{mL}$ ), respectively. Checkerboard assays showed that the combination of $\varepsilon$-PL and Car exerted synergistic effects against $E$. coli and $S$. aureus with fraction inhibitory concentration index (FICI) of 0.375 and 0.5 , respectively. It demonstrated that the combination of $\varepsilon$-PL and Car significantly inhibited the growth of the two strains compared to single treatment. Furthermore, the mode of action of $\varepsilon$-PL $(6.25 \mu \mathrm{g} / \mathrm{mL})$ or Car $(80 \mu \mathrm{g} / \mathrm{mL})$ in inhibiting $E$. coli and $S$. aureus was researched by assessing their changes with regard to cellular membrane integrity, membrane permeability, respiratory activity, and membrane structure. A combination of $\varepsilon$-PL and Car increased the damage to cell membranes and their permeability and led to the release of $260 \mathrm{~nm}$ absorbing materials, decreased respiratory-chain dehydrogenase activity compared with $\varepsilon$-PL or Car treatment alone. These results demonstrated that the combination of $\varepsilon$-PL and Car could be used as a new promising naturally sourced food preservative.
\end{abstract}

Keywords: carvacrol; $\varepsilon$-polylysine; synergistic antimicrobial activity

\section{Introduction}

The Centres for Disease Control (CDC) estimates that each year approximately one in six Americans (or 48 million people) fall sick, of which 128,000 are hospitalized, and 3000 die of foodborne diseases. Therefore, food safety issues caused by foodborne diseases have received widespread attention. Pathogens causing the most foodborne illnesses, hospitalizations, and deaths each year include Escherichia coli O157:H7, Salmonella, Staphylococcus aureus, Listeria monocytogenes, and Campylobacter. In particular, recent studies have reported that meat contaminated with pathogenic bacteria, such as E. coli O157:H7, L. monocytogenes, and
Bacillus cereus, represents a serious public health risk. Some $E$. coli strains are commensal both for human and animal intestines, and Shiga-toxin producing strains are responsible of food-related infections (Pinilla and Brandelli, 2016). Awareness of synthetic additives and preservatives in food processing has led food industries to search for natural additives with a broad spectrum of antimicrobial activities. Food consumers and enterprises urgently need natural alternatives to assure food safety and quality (Saharkhiz et al., 2016).

Essential oils are volatile compounds from plant materials that have been used as naturally derived antimicrobials for food bio-preservatives (Vergis et al., 2015). 
Among the different groups of chemical constituents of essential oils, one of the most effective is carvacrol (Car for short) (Lambert et al., 2001). It has been reported that the essential oils of the oregano and thyme were effective against strains of E. coli (Dorman and Deans, 2010). The major antibacterial component of these oils is Car, which effectively inhibits the growth and survival of several foodborne pathogens, such as $S$. aureus and different strains of $E$. coli. Car exhibits antibacterial activity against the foodborne pathogen $B$. cereus by disrupting the cell membrane. Car reduces intracellular adenosine triphosphatase ATP and membrane potential, leading to dissipation of the $\mathrm{pH}$ gradient and cell death (Ultee et al., 1999). Car is hydrophobic and disrupts the outer membrane of Gram-negative bacteria, releasing lipopolysaccharides and increasing the permeability of the cytoplasmic membrane to ATP (Lambert et al., 2001). Numerous lines of evidence indicate that Car's site of action is the membrane and that Car's mode of action is to increase membrane fluidity and permeability. Car is naturally occurring, but the main obstacle to the use of Car as a food preservative is that it is often not potent as a single compound. Car causes negative organoleptic effects, including a strong flavor and odor, when used at levels necessary to provide antimicrobial effects (Lambert et al., 2001). Many studies suggest that Car is synergistic with other antimicrobial preservatives. Thus, the amount of Car applied to foods could be reduced and the unpleasant effects of high doses of Car could be avoided (Palaniappan and Holley, 2010).

$\varepsilon$-Poly-L-lysine ( $\varepsilon$-PL for short) is a homopolyamino acid characterized by a peptide bond between the carboxyl and $\alpha$-amino groups of 1-lysine. This molecule is composed of a series of 25-35 L-lysine monomers and has a molecular weight of approximately $5000 \mathrm{Da}$ (Sun et al., 2018). $\varepsilon$-PL is derived from metabolites produced by the fermentation of Streptomyces albulus (Li et al., 2014) and is a highly safe natural food preservative. Compared with chemical preservatives, $\varepsilon$-PL is a safer product of biological fermentation that can be broken down into lysine required by the human body (Zahi et al., 2017). In addition, $\varepsilon$-PL also has the advantages of a broad antibacterial spectrum, high temperature resistance, good water solubility, low toxicity, and efficacy in a wide range of $\mathrm{pH}$ values. Regarding its mode of action against $E$. coli, $\varepsilon-\mathrm{PL}$ reduces the amounts of large molecules, soluble cellular proteins, and nucleic acids by damaging cell membranes (Zhang et al., 2018). In addition, $\varepsilon$-PL is believed to electrostatically adsorb onto the cellular membrane, resulting in membrane disruption and abnormal distribution of the cytoplasm (Shima et al., 1984). In addition, $\varepsilon$-PL has been approved as a safe food preservative in China and the United States and has been widely used in the preservation of various foods, such as cooked meat products, fruit and vegetable juices, and egg products. However,
$\varepsilon$-PL can be subject to rapid depletion after initial application and lose activity quickly (Bi et al., 2016). Studies have been performed to improve the effectiveness of $\varepsilon$-PL. For example, Lin et al. (2018) confirmed that the gelatine nanofibers containing thyme essential oil/betacyclodextrin epsilon-polylysine nanoparticles were engineered in order to control the propagation of $C$. jejuni. $\varepsilon$-PL or $\varepsilon$-PL combined with $\mathrm{CO}_{2}$ packaging is effective in controlling the food-borne pathogens, and its covalent immobilization to multi-walled carbon nanotubes is useful in the construction of a nanocomposite with enhanced antibacterial activity (Miya et al., 2016).

In order to improve the antimicrobial activity, a novel combination of antimicrobial agents is extensively used. According to reports, the combination of EOs and other EOs or natural antibacterial agents can achieve a strong inhibitory effect of very low doses and effectively reduce the negatives (Govaris et al., 2010). On the other hand, the antibacterial effect and mechanism of action of the combination of $\varepsilon-\mathrm{PL}$ and Car have not been investigated to date. The objectives of this study were to investigate the synergistic action of the combined substances $(\varepsilon-\mathrm{PL}$ and Car) against E. coli and $S$. aureus using in vitro assays and verify the application feasibility of this combination as a promising new antibacterial agent in food preservation. E. coli was chosen as a model for pathogenic Gram-negative bacteria (Sondi and Salopek-Sondi, 2004), whereas $S$. aureus was selected as a representative strain of Gram-positive bacteria. Both bacteria served as representatives for foodborne diseases. Therefore, our study seeks to elucidate the synergistic bacteriostatic effect of $\varepsilon-\mathrm{PL}$ and Car, and preliminarily investigate their antibacterial mechanism.

\section{Materials and Methods}

\section{Chemical reagents and bacterial strains}

Carvacrol and $\varepsilon$-polylysine were purchased from Shanghai McLean Corporation (Shanghai, China). Iodonitrotetrazolium blue (INT) was obtained from Shanghai Sobo Biotechnology Co., Ltd. (Shanghai, China). Sodium chloride, tryptone, and yeast extract were purchased from Sinopharm Chemical Reagent Co., Ltd. (Beijing, China). In addition, 12- and 24-well cell culture plates were obtained from Corning Incorporated (New York, USA). The BCA protein quantification kit was purchased from Biotech Bioengineering Co., Ltd (Shanghai, China). Two food-related microorganisms were used to assess antimicrobial properties, including Gram-negative E. coli CICC 10664 and Gram-positive S. aureus. CICC 21600. The two strains were obtained from the China Centre of Industrial Culture Collection, CICC (Shanghai, China). Luria-Bertani Broth (LB) (1\% 
tryptone, $0.5 \%$ yeast extract, and $1 \%$ sodium chloride) was used for the growth of bacterial cultures (Shanghai Jingan Biotechnology Co., Ltd, Shanghai, China). The remaining reagents are of analytical grade.

\section{Determination of MIC and MBC}

The minimal inhibitory concentrations (MICs) of $\varepsilon-\mathrm{PL}$ and $\mathrm{Car}$ against bacteria were determined based on Clinical and Laboratory Standards Institute guidelines using the standard broth dilution method as previously described (Chen and Zhong, 2017). First, $100 \mu \mathrm{L}$ of LB liquid culture medium was added to each well of the 96-well plate. Then, $100 \mu \mathrm{L}$ of bacteriostatic agent was added to the first well of each row and mixed thoroughly. Transfer $100 \mu \mathrm{L}$ of the above solution from the first well to the second well, then transfer $100 \mu \mathrm{L}$ from the second well to the third well and repeat until it is added to the 11th well in the same row. The solution to well 11 was mixed, and $100 \mu \mathrm{L}$ was removed. Then, $100 \mu \mathrm{L}$ of S. aureus or E. coli $\left(\sim 10^{7} \mathrm{CFU} / \mathrm{mL}\right)$ diluted with physiological saline was added to wells 1 to 10 and 12 of each row, and $100 \mu \mathrm{L}$ of physiological saline was added to well 11. The above sample was incubated at $37^{\circ} \mathrm{C}$ for $24 \mathrm{~h}$ in a constant temperature incubator. $\mathrm{OD}_{600 \mathrm{~nm}}$ value of each well was detected using SpectraMax iD3 multifunctional microplate reader. The lowest concentration of $\mathrm{Car}$ and $\varepsilon$-PL that inhibits the growth of E. coli or S. aureus in the medium is their MIC.

Refer to the method of Chen et al. (2017) with a slight modification. According to the results of the abovementioned minimum inhibitory concentration (MIC), for negative wells, a $100 \mu \mathrm{L}$ aliquot was spread on the LB medium, and then incubated at $37^{\circ} \mathrm{C}$ for $48 \mathrm{~h}$. The concentration of aseptic growth was determined as MBC.

\section{Checkerboard microdilution tests}

The synergistic interaction between Car and $\varepsilon$-PL was determined using the checkerboard test based on a previous study (Kozak et al., 2018). Serial dilutions of both antimicrobials were mixed to obtain a fixed amount of the first agent and increasing amounts to the second agent in each row (or column). Continuous twofold dilutions of Car and $\varepsilon$-PL were mixed in LB medium. The final concentration of the mixture was $1 / 32$ to 4 times the MIC of Car and 1/128 to 4 times the MIC of $\varepsilon$-PL. The inoculum of each well was adjusted to a final concentration of $1 \times 10^{7} \mathrm{CFU} / \mathrm{mL}$, and the plate was incubated at $37^{\circ} \mathrm{C}$ for $24 \mathrm{~h}$.

In order to evaluate the antibacterial effect of each combination, the following equation was used to analyze the data generated by the checkerboard test according to the Fractional Inhibitory Concentration Index (FICI).

Among them, $\mathrm{MIC}_{\mathrm{A}}$ and $\mathrm{MIC}_{\mathrm{B}}$ are the MIC of the compounds $\mathrm{Car}$ and $\varepsilon$-pL when acting alone, and $\mathrm{C}_{\mathrm{A}}{ }^{\mathrm{COMB}}$ and $\mathrm{C}_{\mathrm{B}}{ }^{\mathrm{COMB}}$ are the MICs of Car and $\varepsilon$-pL in combination. The interaction between $\mathrm{A}$ and $\mathrm{B}$ was interpreted as a synergistic effect $(\mathrm{FICI} \leq 0.5)$, partial synergism $(0.5<\mathrm{FICI}<$ $1.0)$, no effect $(1.0 \leq \mathrm{FICI} \leq 4.0)$, or antagonism (FICI > 4.0) (Oliveira et al., 2010).

\section{Growth kinetic tests}

The growth kinetic test was used to evaluate the synergistic antimicrobial effect of Car and $\varepsilon$-PL against E. coli or S. aureus (Chen et al., 2017). Connect a test tube containing $9 \mathrm{~mL}$ of sterile LB medium to $2 \%$ freshly cultured $S$. aureus or E. coli bacterial solution, and add $1 \mathrm{~mL}$ sample to the test tube with a final concentration of $80 \mu \mathrm{g} /$ $\mathrm{mL}$ Car or $/$ and $6.25 \mu \mathrm{g} / \mathrm{mL} \varepsilon$-PL. Place it in a constant temperature shaker at $37^{\circ} \mathrm{C}$ for shaking culture, take samples every $2 \mathrm{~h}$, and measure the absorbance at $\mathrm{OD}_{600 \mathrm{~nm}}$. The growth curve of E. coli or S. aureus was established according to the correlation between the incubation time and the $\mathrm{OD}_{600 \mathrm{~nm}}$ value.

\section{Measurement of the release of $260 \mathrm{~nm}$ absorbing cellular materials}

The release of UV-absorbing materials was measured using an UV-7504c spectrophotometer according to the method described by Windiasti et al. (2019) and Shi et al. (2017) with some modifications. Bacteria cells cultured overnight in the LB medium were collected by centrifuge at $5000 \mathrm{~g}$ for $15 \mathrm{~min}$ at $4^{\circ} \mathrm{C}$. The pellets were thoroughly rinsed with phosphate buffer (PBS, pH 7.4) and resuspended in phosphate buffer (PBS, pH 7.4). The absorbance of the final cell suspension at $420 \mathrm{~nm}$ was adjusted to 0.7 . The above samples were treated with Car $(80 \mu \mathrm{g} / \mathrm{mL}), \varepsilon-\mathrm{PL}(6.25 \mu \mathrm{g} / \mathrm{mL})$, and Car $(80$ $\mu \mathrm{g} / \mathrm{mL}) / \varepsilon$-PL $(6.25 \mu \mathrm{g} / \mathrm{mL})$, respectively. No antibacterial substance added cell suspensions served as negative controls. Bacterial suspensions were incubated at $37^{\circ} \mathrm{C}$. The $\mathrm{OD}_{260 \mathrm{~nm}}$ was determined at $0,1.0,2.0,3.0$, 4.0 , and $5.0 \mathrm{~h}$ after incubation. After incubation, $5.0 \mathrm{~mL}$ of each sample was collected at each time-point and centrifuged $(11,000 \times g, 10 \mathrm{~min})$, and the supernatants were filtered through a sterile nitrate cellulose membrane $(0.22 \mu \mathrm{m}$, Tianjin Jinteng Technology Co., Ltd.). The $\mathrm{OD}_{260 \mathrm{~nm}}$ value of the supernatant was measured to observe the amount of extracellular UV-absorbing materials released by cells. All the measurements were performed in triplicate. 


\section{Membrane permeability assay}

Propidium iodide (PI) staining was used to assess membrane integrity of S. aureus or E. coli. Log phase S. aureus or E. coli cells $\left(\sim 10^{7} \mathrm{CFU} / \mathrm{mL}\right)$ was treated by $80 \mu \mathrm{g} / \mathrm{mL}$ Car and $6.25 \mu \mathrm{g} / \mathrm{mL} \varepsilon-\mathrm{PL}$ alone or by a combination of 80 $\mu \mathrm{g} / \mathrm{mL}$ Car and $6.25 \mu \mathrm{g} / \mathrm{mL} \varepsilon$-PL, and the sample without treatment was used as the control group. After treatment, bacteria cells were harvested by centrifugation at $8000 \mathrm{~g}$ for $10 \mathrm{~min}$. Then, PI was added to each group and incubated in the dark for $30 \mathrm{~min}$. The membrane permeability of PI-stained cells and the FL3 (red) fluorescence channel was detected under photoexcitation at a wavelength of $488 \mathrm{~nm}$ and $615 \mathrm{~nm}$, respectively, by using the FACS LSRFortessa flow cytometry (Becton, Dickinson and Company, America) (Sun et al., 2017). The data were analyzed by CellQuest Pro software.

\section{Respiratory chain dehydrogenase determination}

E. coli or S. aureus was inoculated into the LB medium and incubated at $37^{\circ} \mathrm{C}$ for $18 \mathrm{~h}$. The bacterial cells were collected by centrifuge for $15 \mathrm{~min}$ and washed with physiological saline. Then, the above pellet was resuspended by $1 \mathrm{~mL}$ of $1 \times$ MIC Car or $\varepsilon$-PL and incubated at room temperature for $3 \mathrm{~h}$.

The bacteria were killed by a water bath at $100^{\circ} \mathrm{C}$ for 15 minutes to destroy the respiratory chain dehydrogenase activity on the surface of the bacteria. A blank control of live bacteria (without inhibitor) and a negative control of dead bacteria were also prepared.. The sample was centrifuged at $4^{\circ} \mathrm{C}$ for $15 \mathrm{~min}$ again and the pellet was collected, washed, and resuspended in $0.9 \mathrm{~mL}$ PBS. Then, $0.1 \mathrm{~mL}$ of the respiratory chain dehydrogenase substrate, namely, $0.5 \%$ iodine nitro tetrazolium chloride (INT), was added to the above samples. The solution was mixed well and incubated at $37^{\circ} \mathrm{C}$ for $1 \mathrm{~h}$ in the dark. A490 nm values of the reactants were measured using a SpectraMax iD3 microplate reader (Meigu Molecular Instruments (Shanghai) Co., Ltd., China) (Cui et al., 2018).

\section{SEM assay}

After treatment for $\varepsilon-\mathrm{PL}, \mathrm{Car}$, or a combination of $\varepsilon-\mathrm{PL}$ and Car, morphological changes of E. coli or S. aureus were observed using Scanning Electronic Microscopy. Fresh cultures of S. aureus or E. coli were diluted with LB medium to $10^{7} \mathrm{CFU} / \mathrm{mL}$. Then, $1 \mathrm{~mL}$ of the diluted bacterial solution was added to the 24-well plate. A sterile circular slide was placed into each well, and the plate was incubated at $37^{\circ} \mathrm{C}$ for $12 \mathrm{~h}$. Then, the bacterial suspension was aspirated and washed thrice with sterile PBS. For the experimental groups, $1 \mathrm{~mL} \varepsilon$-PL $(6.25 \mu \mathrm{g} / \mathrm{mL})$ and $1 \mathrm{~mL}$
Car $(80 \mu \mathrm{g} / \mathrm{mL})$ alone or in combination were added to each well of a 96-well plate. In addition, $1 \mathrm{~mL}$ LB liquid medium was added as a control. After incubating at $37^{\circ} \mathrm{C}$ for $6 \mathrm{~h}$, the slide was removed, washed thrice with PBS, and fixed overnight with $2.5 \%$ glutaraldehyde solution to room temperature. Then, the slide was washed with PBS and subject to gradient dehydration using ethanol $(30,50,60,70,80,90,95$, and $100 \%$; each treatment is $15 \mathrm{~min})$. Then, the slide is soaked in absolute ethanol containing anhydrous sodium sulfate, dried, and sprayed with gold. GeminiSEM 300 field emission scanning electron microscopy is used to observe the cells. The data represent three experiments with similar results (Khlaifat et al., 2019).

\section{Statistical analysis}

All tests were conducted in triplicate. Data were expressed as the mean \pm standard errors. Statistical analyses were performed using SPSS version 13.0 software (SPSS Inc., Chicago, IL, USA), and significant differences were reported with a $95 \%$ confidence interval $(\mathrm{P}<0.05)$.

\section{Results}

\section{MIC and FICl of Car and $\varepsilon-P L$ against tested bacteria}

The growth of $S$. aureus or E. coli was effectively inhibited by Car with an MIC of $320 \mu \mathrm{g} / \mathrm{mL}$. Moreover, their growth was also effectively inhibited by $\varepsilon$-PL with MICs of $12.5 \mu \mathrm{g} / \mathrm{mL}$ and $25 \mu \mathrm{g} / \mathrm{mL}$, respectively (Table 1 ). The synergistic bacteriostatic effect of Car and $\varepsilon$-PL was evaluated because two bacteriostatic agents with different bacteriostatic mechanisms may produce a synergistic effect. Specifically, $80 \mu \mathrm{g} / \mathrm{mL}$ Car (1/4 MIC) and $6.25 \mu \mathrm{g} /$ mL $\varepsilon$-PL (1/2 MIC) exhibited synergistic antibacterial activity against $S$. aureus and $E$. coli, and their FICI values are 0.5 and 0.375 , respectively.

In this research, Car and $\varepsilon$-PL alone or in combination showed different antibacterial activities against the tested strains based on the MIC values as shown in Table 1. Synergistic effects between Car and $\varepsilon$-PL were measured by broth dilution checkerboard assay. The bacteriostatic concentration indexes value of $\mathrm{Car}+\varepsilon$-PL against $S$. aureus was 0.5 , which indicates that they have a synergistic effect. The combined antibacterial effect of Car $+\varepsilon$-PL on $S$. aureus is two times higher than that of any single agent. In addition, Car $+\varepsilon$-PL's bacteriostatic concentration indexes value of $E$. coli is 0.375 , which also indicates the synergistic effect on Car and $\varepsilon$-PL. The combined bacteriostatic activity of Car and $\varepsilon$-PL for E. coli was increased two and four times, compared with the single components. In conclusion, the best antibacterial activity 
Table 1. The inhibitory activity of Carvacrol orland $\varepsilon$-Polylysine against $S$. aureus or E. coli.

\begin{tabular}{llllllll} 
Strains & \multicolumn{2}{c}{ MIC $(\mu \mathrm{g} / \mathrm{mL})$} & & & FICI & Interpretation \\
\cline { 2 - 3 } & Car & $\varepsilon-\mathrm{PL}$ & & Car & $\varepsilon-\mathrm{PL}$ & & \\
\hline S. aureus & 320 & 12.5 & 80 & 6.25 & 0.5 & Synergism \\
E. coli & 320 & 25 & 80 & 6.25 & 0.375 & Synergism \\
\hline
\end{tabular}

MIC, Minimal inhibitory concentration; FIC, fractional inhibitory concentration; $\mathrm{FICl}$, fractional inhibitory concentration index.

was obtained using a combination of $\varepsilon-\mathrm{PL}$ and Car with FIC index values of 0.375 and 0.5 , respectively, yielding a synergistic effect on the tested microorganisms. This study demonstrated that $\varepsilon$-PL and Car in combination effectively inhibited $S$. aureus and E. coli growth based on FICI values.

\section{Growth curve determination}

To further prove the synergistic antimicrobial effect of the two reagents, growth dynamics of $E$. coli and $S$. aureus in Luria-Bertani culture medium as measured by $\mathrm{OD}_{600}$ ${ }_{n m}$, as shown in Figure 1. When $80 \mu \mathrm{g} / \mathrm{mL}$ Car and 6.25 $\mu \mathrm{g} / \mathrm{mL} \varepsilon-\mathrm{PL}$ were applied individually, the growth curves followed the same trend as the control. In contrast, the growth of $E$. coli and $S$. aureus was completely prevented by the combination of Car and $\varepsilon$-PL during the $24 \mathrm{~h}$ incubation with no noticeable change in $\mathrm{OD}_{600 \mathrm{~nm}}$. The results further confirmed that Car and $\varepsilon$-PL exhibit a synergistic antibacterial effect against E. coli and S. aureus.

\section{Release of the release of $260-\mathrm{nm}$ absorbing cellular materials}

Cytoplasmic membrane permeability was determined based on UV-absorbing release materials, as presented in Figure 2. The $\mathrm{OD}_{260 \mathrm{~nm}}$ value of the group treatment

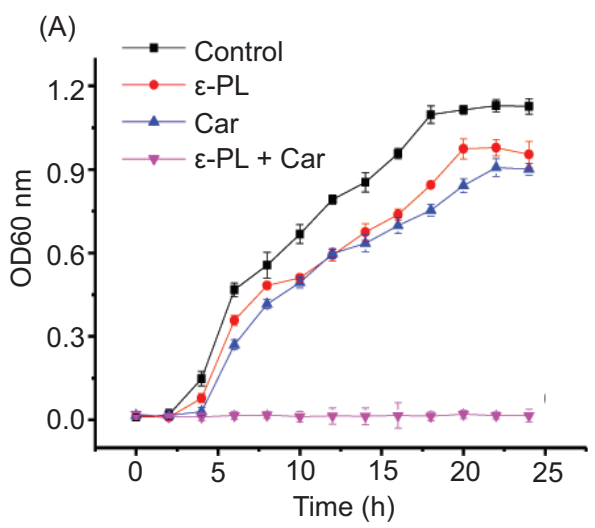

for Car $+\varepsilon$-PL is higher than that of either alone, which indicated that more 260-nm absorbing materials (these materials are assumed to be primarily DNA, RNA, and metabolites (Teethaisong et al., 2014)) was released outside the cells. When E. coli was exposed to Car or $\varepsilon-\mathrm{PL}$ alone, the release of cellular components increased significantly with time, and the OD values increased to 0.432 and 0.304 at $5 \mathrm{~h}$, respectively. Compared with other groups, the concentration of cell components in the suspension treated with Car combined with $\varepsilon$-PL at OD $260 \mathrm{~nm}$ increased to 0.591 at $5 \mathrm{~h}$. When S. aureus was exposed to Car or $\varepsilon$-PL alone, the release of cell components increased significantly with time, and the OD values increased to 0.351 and 0.317 at $5 \mathrm{~h}$. However, compared with other groups, the concentration of cell components in the suspension treated with Car combined with $\varepsilon$-PL at OD260 $\mathrm{nm}$ increased to 0.548 at $5 \mathrm{~h}$. This result suggests that the cytoplasmic membrane permeability was increased when treated with Car and $\varepsilon$-PL in combination and also illustrates the synergistic effect between them.

\section{Membrane permeability analysis}

Changes in the integrity of the cytoplasmic membrane of $E$. coli and $S$. aureus cells were assessed by propidium iodide (PI), a membrane-impermeant dye, via flow cytometric analysis. PI is a nuclear staining reagent that stains

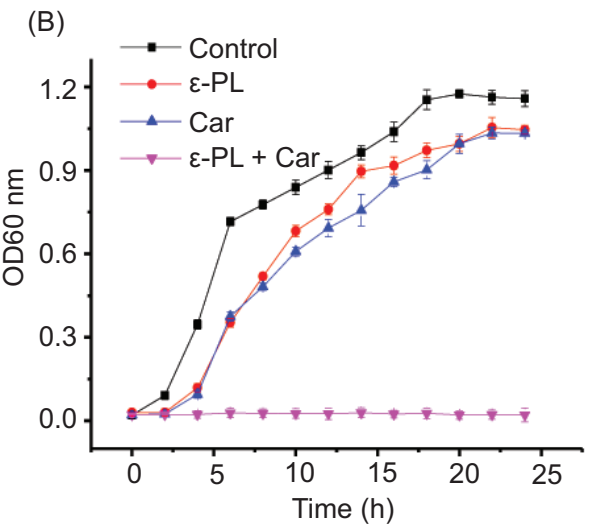

Figure 1. Growth dynamics curves for Car and $\varepsilon$-PL alone or in combination against E. coli CICC 10664 (A) and S. aureus CICC 21600 (B) in LB. The strains were treated with $80 \mu \mathrm{g} / \mathrm{mL}$ Car and $6.25 \mu \mathrm{g} / \mathrm{mL} \varepsilon$-PL alone or in combination. The starting inoculum contained $10^{6} \mathrm{CFU} / \mathrm{mL}$. Values are the means of three independent experiments with SD indicated by vertical bars. 

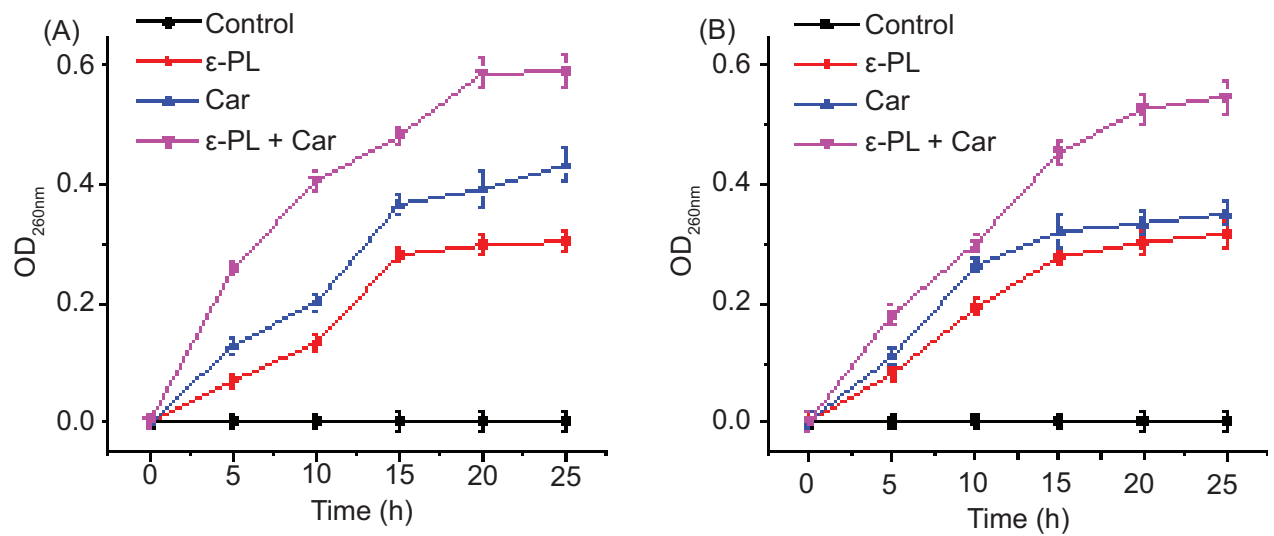

Figure 2. Effects of Car and $\varepsilon$-PL alone or in combination at $1 \times$ MIC on the UV absorption at $260 \mathrm{~nm}$ of E. coli CICC 10664 (A) and S. aureus CICC 21600 (B) at different time points. Error bars are \pm SD of the means.

DNA. It cannot pass through the cell membrane of living cells, but it can pass through damaged cell membranes and bind to nucleic acids in the nucleus. PI is embedded in double-stranded DNA and releases red fluorescence. The dot plots of $E$. coli cells stained with PI are shown in Figure 3.P2 zone is PI positive (PI+). Compared with the control group (Figure 3A1), the $\varepsilon-\mathrm{PL}(6.25 \mu \mathrm{g} / \mathrm{mL})$ treatment group and the Car $(80 \mu \mathrm{g} / \mathrm{mL})$ treatment group yielded 2.1 and $29.8 \%$ E. coli deaths, respectively (Figure $3 \mathrm{~B} 1$ and $\mathrm{C} 1)$. However, $\varepsilon-\mathrm{PL}^{+} \mathrm{Car}$ treatment caused up to $62.4 \%$ E. coli deaths (Figure 3D1). Compared with the control group (Figure 3A2), $\varepsilon$-PL $(6.25 \mu \mathrm{g} / \mathrm{mL})$ and Car $(80 \mu \mathrm{g} / \mathrm{mL})$ treatment induced 5.2 and $12.2 \%$ $S$. aureus deaths, respectively (Figure $3 \mathrm{~B} 2$ and $\mathrm{C} 2$ ). However, $\varepsilon-\mathrm{PL}^{+}$Car treatment caused up to $58.3 \%$
S. aureus deaths (Figure 3D2). The results showed that the combination of $\varepsilon-\mathrm{PL}+$ Car caused severe cell damage and that $\varepsilon$-PL could significantly improve the antibacterial effect of Car against $E$. coli and $S$. aureus.

\section{Inhibition of respiratory chain dehydrogenase in pathogenic bacteria}

The effect of bacteriostatic agents on cell membrane metabolic activity was studied by measuring respiratory chain dehydrogenase activity. The effect of $\varepsilon-\mathrm{PL} / \mathrm{Car}$ on respiration chains dehydrogenase activity of $E$. coli and $S$. aureus cells are shown in Figure 4. The results showed that the respiratory-chain dehydrogenase activity in
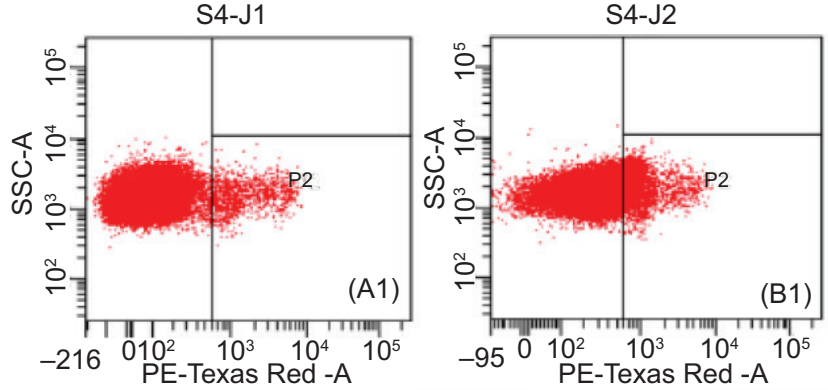

S4-D1

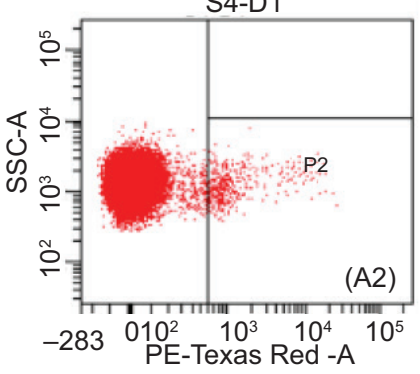

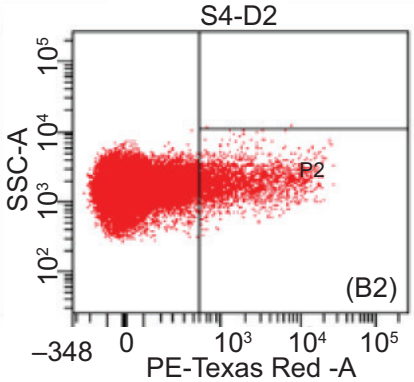
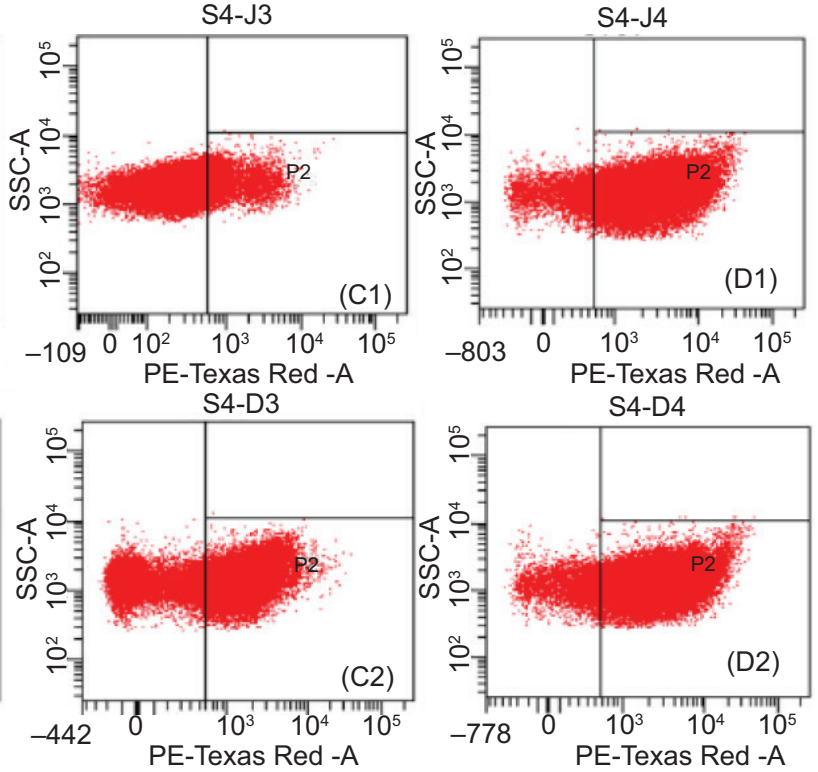

Figure 3. Flow cytometry dot plots of E. coli CICC 10664 cells (A1-D1) and S. aureus CICC 21600 cells (A2-D2). A1 and A2, untreated cells; B1 and B2, cells treated with $\varepsilon-\mathrm{PL}$; $\mathrm{C} 1$ and $\mathrm{C2}$, cells treated with Car; D1 and D2, cells treated with Car and $\varepsilon$-PL. Car concentration, $80 \mu \mathrm{g} / \mathrm{mL} ; \varepsilon$-PL concentration, $6.25 \mu \mathrm{g} / \mathrm{mL}$. 
the cells treatment for $6.25 \mu \mathrm{g} / \mathrm{mL} \varepsilon$-PL was the same as that in without treated cells (control A). In addition, enzyme activity in cells treated with $80 \mu \mathrm{g} / \mathrm{mL}$ Car was slightly decreased, compared to the untreated group. Interestingly, $6.25 \mu \mathrm{g} / \mathrm{mL} \varepsilon-\mathrm{PL}$ and $80 \mu \mathrm{g} / \mathrm{mL}$ Car inhibited $85 \%$ of respiratory chain dehydrogenase activity in E. coli and $61.6 \%$ of it in $S$. aureus. The result shows that the $\varepsilon$-PL/Car combination has a synergistic antibacterial effect on S. aureus and E. coli.

Thus, the reduction in the respiratory chain dehydrogenase activity caused by $\varepsilon$-PL/Car might inhibit normal respiration in cells, hinder bacteria growth, and even kill bacteria. The results suggested that $\varepsilon$-PL and Car exerted synergistic antibacterial effect against $E$. coli and S. aureus.

\section{SEM observations}

Pathogenic bacteria (S. aureus and E. coli) were treated for $3 \mathrm{~h}$ with $\varepsilon$-PL and Car alone or in combination using relevant MIC values (Car $80 \mu \mathrm{g} / \mathrm{mL}$ Car and $6.25 \mu \mathrm{g} / \mathrm{mL}$ $\varepsilon$-PL). Bacteria were then observed by SEM to investigate the resulting morphological changes. SEM was used to examine the cell surface. Nontreated cells were intact (regular rod) and exhibited a smooth surface, as noted in Figure 5A1. In contrast to the control, E. coli cells treated with $\varepsilon$-PL had irregular, withered, and coarse surfaces (Figure 5A2), indicating that cytoplasmic material might be released into the extracellular medium. Cells treated with Car exhibited slight surface damage (Figure 5A3), while Car $+\varepsilon$-pL treatment caused extensive surface damage to most cells. Specifically, both severe cell surface depression and cytoplasmic atrophy were observed (Figure 5A4). Untreated S. aureus exhibited intact cell membranes and plump round cells (Figure 5B1). The surface of some of the cells treated with $\varepsilon-\mathrm{PL}$ and cells treated with Car were damaged, wrinkled, and slightly irregular (Figure 5B2 and B3), while $\varepsilon$-PL + Car treatment caused extensive surface damage to most cells, including a sunken cell surface and shrinking cytoplasm (Figure 5B4). SEM observations confirmed that the structural integrity of the cells was damaged, and considerable morphological changes were noted in E. coli and $S$. aureus. The antibacterial effects of Car combined with $\varepsilon$-PL could be attributed to their pronounced deleterious effects on the bacterial cell membrane, potentially causing leakage of intracellular substances and complete cellular destruction.

\section{Discussion}

Effective food biopreservatives are needed to enhance food safety and quality in the food industry. Naturally produced antimicrobial compounds are acceptable agents to prevent the growth of undesirable organisms in food products. Carvacrol is a kind of monoterpenoid phenol derivative, primarily found in essential oils of herbs such as thyme and oregano. The biological properties of carvacrol have been extensively studied to prove its potential use in food preservation. However, the application of Car is limited due to the adverse sensory reaction caused by the amount of Car. The combination of Car with other antibacterial ingredients not only reduces the dosage and cost of Car but also widens its antibacterial spectrum and improves its application efficiency (Sharma et al., 2020; Wijesundara et al., 2021). This study verified the antibacterial effects of carvacrol and $\varepsilon$-PL alone, and in combination with $E$. coli and $S$. aureus. The synergistic effect of Car and $\varepsilon$-PL enhances their antibacterial activity
(A)

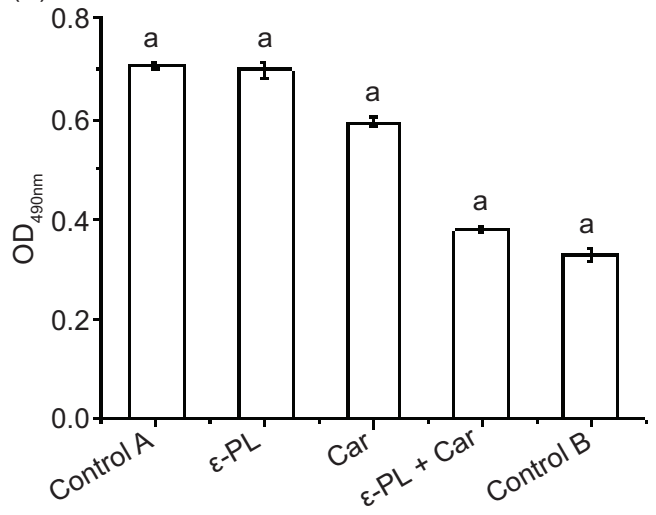

(B)

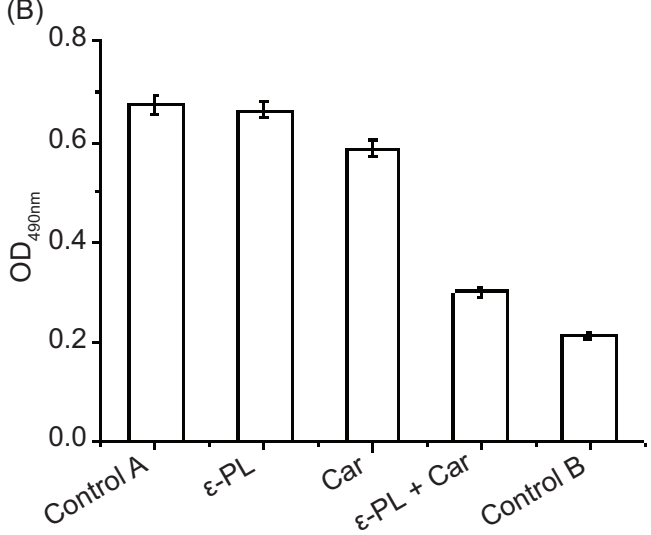

Figure 4. Inhibition of pathogenic bacteria respiratory chain dehydrogenase. (A) E. coli CICC 10664, (B) S. aureus CICC 21600. Control A: Live bacteria control. Control B: Dead bacteria control. The strains were treated with $80 \mu \mathrm{g} / \mathrm{mL} \mathrm{Car}$ and $6.25 \mu \mathrm{g} / \mathrm{mL}$ $\varepsilon$-PL, alone or in combination. The starting inoculum was $10^{6} \mathrm{CFU} / \mathrm{mL}$. Values are the means of three independent experiments with SD indicated by vertical bars. 

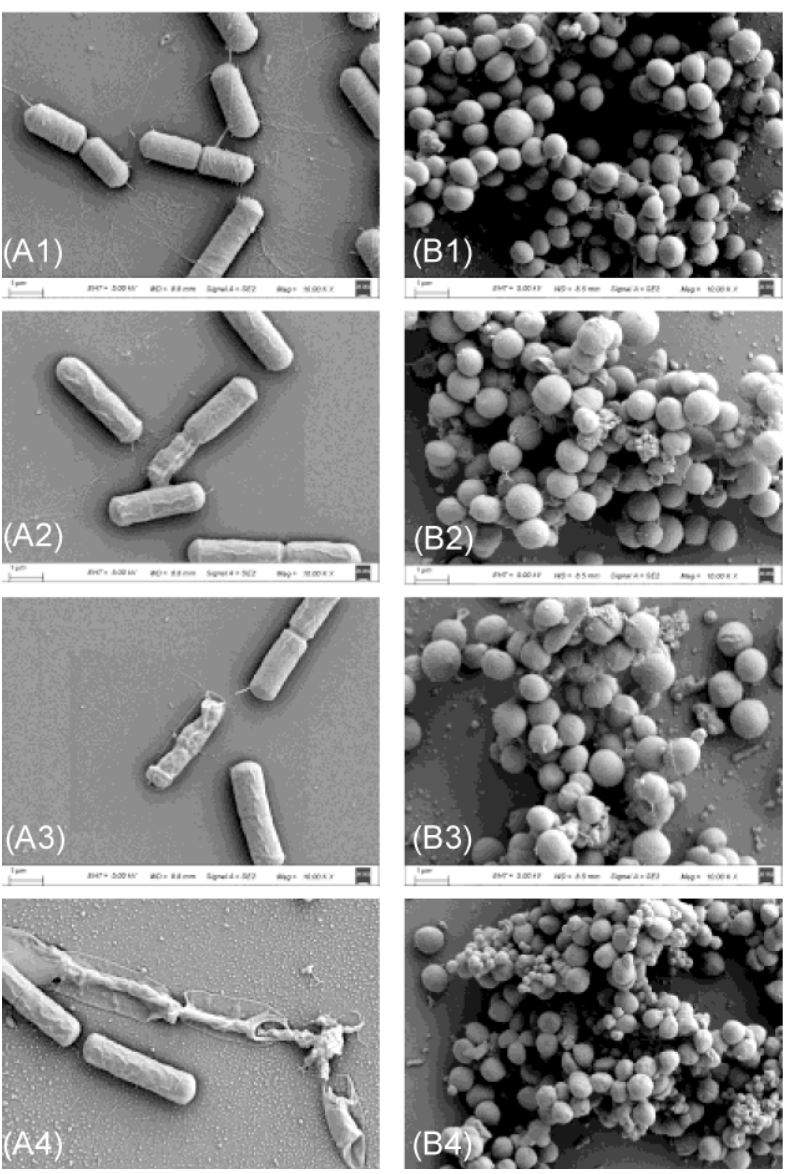

Figure 5. SEM observation of E. coli CICC 10664 cells (A1A4) and S. aureus CICC 21600 cells (B1-B4) exposed to Car and $\varepsilon-P L$ alone and in combination. $A 1$ and $B 1$, untreated cells; $\mathrm{A} 2$ and $\mathrm{B} 2$, cells treated with $\varepsilon-\mathrm{PL} ; \mathrm{A} 3$ and $\mathrm{B} 3$, cells treated with Car; $\mathrm{A} 4$ and $\mathrm{B} 4$, cells treated with Car and $\varepsilon-\mathrm{PL}$.

$(\mathrm{P}<0.05)$. The MIC values of Car were greater than those for $\varepsilon$-PL against E. coli and S. aureus. The MIC values of $\varepsilon$-PL against $S$. aureus and E. coli were reported to be $31.25-62.50 \mu \mathrm{g} / \mathrm{mL}$ and $15.63-31.25 \mu \mathrm{g} / \mathrm{mL}$ respectively. MIC values of $75-375 \mu \mathrm{g} / \mathrm{mL}$ Car were reported against S. aureus and E. coli (Guarda et al., 2011). The combinations of citral and carvacrol, cinnamaldehyde and thymol, carvacrol and eugenol, thymol and eugenol have also been reported to have synergistic effects (Pei et al., 2009; Zanini et al., 2014). The library of natural substances with synergistic effects should be expanded in the future.

Several studies have reported the antibacterial effects of Car or $\varepsilon$-PL on pathogen growth when used in combination with other chemical compounds. Cao et al. (2021) researched the synergistic effects of carvacrol, citral, thy$\mathrm{mol}$, and caprylic acid, and the results indicated that the combination of citral and carvacrol showed a synergistic effect in inhibiting the growth of Cronobacter sakazakii
CICC 21544 (Cao et al., 2021). De Souza et al. (2020) analyzed the synergistic antimicrobial action of chitosan-gelatin-based active biopolymers combined with essential oils (EOs) against foodborne microorganisms, S. aureus and E. coli strains. Fang et al. (2015) evaluated the antibacterial effect of the combination of $\varepsilon-\mathrm{PL}$ and nisin against Enterococcus faecalis strains. The combination of $\varepsilon$-PL and nisin showed synergistic antibacterial activity against three Enterococcus strains. In the present study, our results indicated that Car and $\varepsilon$-PL are bacteriostatic agents with synergistic effects, which could be used for the control of pathogenic microorganisms. The activity of EOs and their components can affect both the cell envelope and cytoplasm. Their hydrophobic nature allows them to penetrate bacterial cell membranes and alter membrane structure and function (Filomena et al., 2013). Car is a hydrophobic compound that affects cell membranes by changing fatty acid composition, subsequently affecting membrane fluidity and permeability (Swamy et al., 2016). This action can lead to the disruption of proteins, DNA, RNA, or polysaccharides, depolarizing their potential and resulting in the death of the target microorganisms (Wu et al., 2009). Thus, the leakage of intracellular substances is an important sign of cell membrane damage. $\varepsilon$-PL exhibits a wide antimicrobial spectrum against Gram-negative and Gram-positive bacteria, yeasts, and molds. Different from the antibacterial mechanism of car, $\varepsilon$-PL mainly hinders DNA replication through insertion into the double helix structure, thereby inhibiting the growth of pathogenic bacteria (Liu et al., 2015). In the present study, the following ergistic antibacterial mechanism of Car and $\varepsilon$-PL has been proposed. Car rapidly destroys fluidity and permeability of bacteria membranes by changing fatty acid composition, and subsequently $\varepsilon$-PL enters the cell, interacts with DNA, and eventually hinders DNA replication. Synergizing the action of different bacteriostatic agents is one of the strategies to effectively control pathogenic bacteria; this reduces the use of each bacteriostatic agent in food. It is believed that Car might bind to cell membranes and then penetrate into the phospholipid bilayer. In this study, it is observed that the damage to the cell membrane permeability of the target strain caused by the synergistic effect of Car and $\varepsilon-\mathrm{PL}$ is their main action. Content of UV-absorbing materials released at $260 \mathrm{~nm}$ showed that both Car and $\varepsilon$-PL act on the lipopolysaccharide layer in E. coli and S. aureus, and change the permeability of the outer cell membrane. These results are consistent with those previously reported by Lv et al. (2011). In addition, combined with the result of reduced dehydrogenase activity in the cellular respiratory chain, it is speculated that Car might also alter membrane permeability by destroying the electron transport system, leading to an increase in the permeability of the inner membrane, which in turn leads to the leakage of intracellular substances. To clarify the morphological changes of cells 
caused by Car and $\varepsilon$-PL, the alterations to bacterial membrane integrity were examined by SEM. Pathogenic bacteria (S. aureus and E. coli) exposed to $\varepsilon$-PL and Car alone or in combination using relevant MIC for $3 \mathrm{~h}$ showed degenerative changes of cytoplasmic membranes, and this leads to leakage of intracellular contents.

\section{Conclusion}

In the present study, we evaluated the antibacterial activity of the combined biocides (carvacrol and $\varepsilon$-polylysine) to test the potential of this new group of food preservatives in preventing food-borne pathogens. The results revealed that the combination of Car and $\varepsilon$-PL displayed good synergistic antibacterial activities against $E$. coli and $S$. aureus strains, increasing the effectiveness of either antibacterial agent alone. Furthermore, these results indicated that the application of a combination of $\varepsilon-\mathrm{PL}$ and Car can not only effectively control the number of $E$. coli and $S$. aureus but also reduce the amount of the two natural preservatives, $\varepsilon$-PL and Car. In addition, preliminary studies on the mechanism of action have shown that cell morphology and physiology are damaged by Car and $\varepsilon$-PL, resulting in the loss of intracellular components and the death of pathogens. Taken together, the combination of $\varepsilon$-PL and Car is an effective natural antibacterial agent, which has shown great application potential in the control of E. coli and S. aureus contamination.

\section{Acknowledgements}

This research was supported by the China Postdoctoral Science Foundation (grant no. 2018M632393), the Natural Science Foundation of the Jiangsu Higher Education Institutions of China (grant no. 20KJA550002), and the Science and Technology Innovation Fund for College Students of Yangzhou University (grant no. x20180856). The authors are grateful to Yangzhou University Testing Centre for the technical collaboration.

\section{Conflict of Interest}

The authors declare that they have no known competing financial interests or personal relationships that could influence the work reported in this paper.

\section{References}

Bi, L., Yang, L., Bhunia, A.K. and Yao, Y., 2016. Emulsion stabilized with phytoglycogen octenyl succinate prolongs the antimicrobial efficacy of $\varepsilon$-poly-l-lysine against Escherichia coli O157: H7.
LWT-Food Science and Technology 70: 245-251. https://doi. org/10.1016/j.lwt.2016.02.049

Cao, Y.F., Zhou, D.G., Zhang, X.W., Xiao, X.L., Yu, Y.G. and Li, X.F., 2021. Synergistic effect of citral and carvacrol and their combination with mild heat against Cronobacter sakazakii CICC 21544 in reconstituted infant formula. LWT-Food Science and Technology 138: 110617. https://doi.org/10.1016/j. lwt.2020.110617

Chen, H.Q. and Zhong, Q.X., 2017. Lactobionic acid enhances the synergistic effect of nisin and thymol against Listeria monocytogenes Scott A in tryptic soy broth and milk. International Journal of Food Microbiology 260: 36-41. https://doi.org/10.1016/j. ijfoodmicro.2017.08.013

Cui, H.Y., Dai, Y.J. and Lin, L., 2018. Enhancing antibacterial efficacy of nisin in pork by poly- $\gamma$-glutamic acid/poly-l-lysine nanoparticles encapsulation. Journal of Food Safety 38(4): e12475. https:// doi.org/10.1111/jfs.12475

De Souza, V.V.M.A., Crippa, B.L., De Almeida, J.M., Iacuzio, R., Setzer, W.N., Sharifi-Rad, J. and Cirone Silva, N.C., 2020. Synergistic antimicrobial action and effect of active chitosangelatin biopolymeric films containing Thymus vulgaris, Ocimum basilicum and Origanum majorana essential oils against Escherichia coli and Staphylococcus aureus. Cellular and Molecular Biology 66(4): 214-223. https://doi.org/10.14715/ $\mathrm{cmb} / 2020.66 .4 .26$

Dorman, H. and Deans, S.G., 2010. Antimicrobial agents from plants: antibacterial activity of plant volatile oils. Journal of Applied Microbiology 88(2): 308-316. https://doi. org/10.1046/j.1365-2672.2000.00969.x

Filomena, N., Florinda, F., Laura, D.M., Raffaele, C. and Vincenco, D.F., 2013. Effect of essential oils on pathogenic bacteria. Food Control 6(12): 1451-1474. https://doi.org/10.3390/ph6121451

Govaris, A., Solomakos, N., Pexara, A. and Chatzopoulou, P.S., 2010. The antimicrobial effect of oregano essential oil, nisin and their combination against Salmonella Enteritidis in minced sheep meat during refrigerated storage. International Journal of Food Microbiology 137(2): 175-180. https://doi.org/10.1016/j. ijfoodmicro.2009.12.017

Guarda, A., Rubilar, J.F., Miltz, J. and Galotto, M.J., 2011. The antimicrobial activity of microencapsulated thymol and carvacrol, International Journal of Food Microbiology 146(2): 144-150. https://doi.org/10.1016/j.ijfoodmicro.2011.02.011

Khlaifat, A.M., Al-limoun, M.O., Khleifat, K.M., Al Tarawneh, A.A., Qaralleh, H., Rayyan, E. and Alsharafa, K.Y., 2019. Antibacterial synergy of Tritirachium oryzae-produced silver nanoparticles with different antibiotics and essential oils derived from Cupressus sempervirens and Asteriscus graveolens (Forssk). Tropical Journal of Pharmaceutical research 18(12): 2605-2616. https://doi.org/10.4314/tjpr.v18i12.21

Kozak, S.M., Brown, S.R.B., Bobak, Y. and D’Amico, D.J., 2018. Control of Listeria monocytogenes in whole milk using antimicrobials applied individually and in combination. Journal of Dairy Science 101(3): 1889-1900. https://doi.org/10.3168/ jds.2017-13648

Lambert, R.J.W., Skandamis, P.N., Coote P.J. and Nychas, G.J.E., 2001. A study of the minimum inhibitory concentration and 
mode of action of oregano essential oil, thymol and carvacrol. Journal of Applied Microbiology 91(3): 453-462. https://doi. org/10.104.6/j.1365-2672.2001.01428.x

Li, Y.Q., Han, Q., Feng, J.L., Tian, W.L. and Mo, H.Z., 2014. Antibacterial characteristics and mechanisms of $\varepsilon$-poly-lysine against Escherichia coli and Staphylococcus aureus. Food Control 43: 22-27. https://doi.org/10.1016/j.foodcont.2014.02.023

Lin, L., Zhu, Y.L. and Cui, H.Y., 2018. Electrospun thyme essential oil/ gelatin nanofibers for active packaging against Campylobacter jejuni in chicken. LWT-Food Science and Technology 97: 711718. https://doi.org/10.1016/j.lwt.2018.08.015

Liu, H.X., Pei, H.B., Han, Z.N., Feng, G.L. and Li, D.P., 2015. The antimicrobial effects and synergistic antibacterial mechanism of the combination of epsilon-polylysine and nisin against Bacillus subtilis. Food Control 47: 444-450. https://doi.org/10.1016/j. foodcont.2014.07.050

Lv, F., Liang, H., Yuan, Q.P. and Li, C.F., 2011. In vitro antimicrobial effects and mechanism of action of selected plant essential oil combinations against four food-related microorganisms. Food Research International 44(9): 3057-3064. https://doi. org/10.1016/j.foodres.2011.07.030

Miya, S., Takahashi, H., Hashimoto, M., Nakazawa, M., Kuda, T., Koiso, H. and Kimura, B., 2016. Development of a controlling method for Escherichia coli O157: H7 and Salmonella spp. in fresh market beef by using polylysine and modified atmosphere packaging. Food Control 37: 62-67. https://doi.org/10.1016/j. foodcont.2013.09.028

Oliveira, C.E.V., Stamford, T.L.M., Neto, N.J.G. and De Souza, E.L., 2010. Inhibition of Staphylococcus aureus in broth and meat broth using synergies of phenolics and organic acids. International Journal of Food Microbiology 137: 312-316. https://doi.org/10.1016/j.ijfoodmicro.2009.11.019

Palaniappan, K. and Holley, R.A., 2010. Use of natural antimicrobials to increase antibiotic susceptibility of drug resistant bacteria. International Journal of Food Microbiology 140(2-3): 164-168. https://doi.org/10.1016/j.ijfoodmicro.2010.04.001

Pei, R.S., Zhou, F., Ji, B.P. and Xu, J., 2009. Evaluation of combined antibacterial effects of eugenol, cinnamaldehyde, thymol, and carvacrol against E-coli with an improved method. Journal of Food Science 74(7): M379-M383. https://doi. org/10.1111/j.1750-3841.2009.01287.x

Pinilla, C.M.B. and Brandelli, A., 2016. Antimicrobial activity of nanoliposomes co-encapsulating nisin and garlic extract against Gram-positive and Gram-negative bacteria in milk. Innovative Food Science and Emerging Technologies 36: 287-293. https:// doi.org/10.1016/j.ifset.2016.07.017

Saharkhiz, M.J., Zomorodian, K., Taban, A., Pakshir, K., Heshmati, K. and Rahimi, M.J., 2016. Chemical composition and antimicrobial activities of three satureja species against foodborne pathogens. Journal of Essential oil Bearing Plants 19(8): 1984-1992. https://doi.org/10.1080/0972060X.2016.1252697

Sharma, K., Guleria, S., Razdan, V.K. and Babu, V., 2020. Synergistic antioxidant and antimicrobial activities of essential oils of some selected medicinal plants in combination and with synthetic compounds. Industrial Crops and Products 154: 112569. https:// doi.org/10.1016/j.indcrop.2020.112569
Shi, C., Zhao, X.C., Meng, R.Z., Liu, Z.J., Zhang, G.N. and Guo, N., 2017. Synergistic vantimicrobial effects of nisin and p-Anisaldehyde on Staphylococcus aureus in pasteurized milk. LWT-Food Science and Technology 84: 222-230. https://doi.org/10.1016/j. lwt.2017.05.056

Shima, S., Matsuoka, H., Iwamoto, T. and Sakai, H., 1984. Antimicrobial action of $\varepsilon$-poly-L-lysine. Journal of Antibiotics 37(11): 1449-1455. https://doi.org/10.7164/antibiotics.37.1449

Sondi, I. and Salopek-Sondi, B., 2004. Silver nanoparticles as antimicrobial agent: a case study on E. coli as a model for Gramnegative bacteria. Journal of Colloid \& Interface Science 275: 177-182. https://doi.org/10.1016/j.jcis.2004.02.012

Sun, G.Z., Yang, Q.C., Zhang, A.C., Guo, J., Liu, X.J., Wang, Y. and $\mathrm{Ma}, \mathrm{Q}$., 2018. Synergistic effect of the combined bio-fungicides $\varepsilon$-poly-l-lysine and chitooligosaccharide in controlling grey mould (Botrytis cinerea) in tomatoes. International Journal of Food Microbiology 276: 46-53. https://doi.org/10.1016/j. ijfoodmicro.2018.04.006

Sun, Z.L., Li, P.P., Liu, F., Bian, H., Wang, D.Y., Wang, X.M., Zou, Y., Sun, C. and Xu, W.M., 2017. Synergistic antibacterial mechanism of the Lactobacillus crispatus surface layer protein and nisin on Staphylococcus saprophyticus. Scientific Reports 7(1): 265. https://doi.org/10.1038/s41598-017-00303-8

Swamy, M.K., Akhtar, M.S. and Sinniah, U.R., 2016. Antimicrobial properties of plant essential oils against human pathogens and their mode of action: an updated review. Evidence-Based Complementary and Alternative Medicine 2016 (3012462): 3012462. https://doi.org/10.1155/2016/3012462

Teethaisong, Y., Autarkool, N., Sirichaiwetchakoon, K., Krubphachaya, P., Kupittayanant, S. and Eumkeb, G., 2014. Synergistic activity and mechanism of action of Stephania suberosa Forman extract and ampicillin combination against ampicillin-resistant Staphylococcus aureus. Journal of Biomedical Science 21(1): 90. https://doi.org/10.1186/s12929-014-0090-2

Ultee, A., Kets, E.P. and Smid, E.J., 1999. Mechanisms of action of carvacrol on the food-borne pathogen Bacillus cereus. Applied and Environmental Microbiology 65(10): 4606-4610. https:// doi.org/10.1128/aem.65.10.4606-4610.1999

Vergis, J., Gokulakrishnan, P., Agarwal, R.K. and Kumar, A., 2015. Essential oils as natural food antimicrobial agents: a review. Critical Reviews in Food Science and Nutrition 55(10): 13201323. https://doi.org/10.1080/10408398.2012.692127

Wijesundara, N.M., Lee, S.F., Cheng, Z.Y., Davidson, R. and Rupasinghe, H.P.V., 2021. Carvacrol exhibits rapid bactericidal activity against Streptococcus pyogenes through cell membrane damage. Science Reports 11(1): 1487. https://doi.org/10.1038/ s41598-020-79713-0

Windiasti, G., Feng, J.S., Ma, L.N., Hu, Y.X., Hakeem, M.J., Amoaka, K., Delaquis, P. and Lu, X.N., 2019. Investigating the synergistic antimicrobial effect of carvacrol and zinc oxide nanoparticles against Campylobacter jejuni. Food Control 96: 39-46. https://doi.org/10.1016/j.foodcont.2018.08.028

Wu, V.C.H., Qiu, X.J., de los Reyes, B.G., Lin, C.S. and Pan, Y.P., 2009. Application of cranberry concentrate (Vaccinium macrocarpon) to control Escherichia coli O157: H7 in ground beef and its antimicrobial mechanism related to the downregulated 
slp, hdeA and cfa. Food Microbiology 26(1): 32-38. https://doi. org/10.1016/j.fm.2008.07.014

Zahi, M.R., El Hattab, M., Liang, H. and Yuan, Q., 2017. Enhancing the antimicrobial activity of d-limonene nanoemulsion with the inclusion of $\varepsilon$-polylysine. Food Chemistry 221: 18-23. https:// doi.org/10.1016/j.foodchem.2016.10.037

Zanini, S.F., Silva-Angulo, A.B., Rosenthal, A., Rodrigo, D. and Martinez, A., 2014. Effect of citral and carvacrol on the susceptibility of Listeria monocytogenes and Listeria innocua to antibiotics. Letters in Applied Microbiology 58(5): 486-492. https://doi.org/10.1111/lam.12218

Zhang, X.W., Shi, C., Liu, Z.J., Pan, F.G., Meng, R.Z. Bu, X.J., Xing, H.Q. Deng, Y.H., Guo, N. and Yu, L., 2018. Antibacterial activity and mode of action of $\varepsilon$-polylysine against Escherichia coli O157: H7. Journal of Medical Microbiology 67: 838-845. https://doi.org/10.1099/jmm.0.000729 